\title{
Nonlinear Dynamics Mechanism of Rock Burst Induced by the Instability of the Layer-Crack Plate Structure in the Coal Wall in Deep Coal Mining
}

\author{
Yanlong Chen, ${ }^{1,2}$ Aihong Lu, ${ }^{2}$ Xianbiao Mao, ${ }^{2}$ Ming Li, ${ }^{1}$ and Lianying Zhang ${ }^{3}$ \\ ${ }^{1}$ State Key Laboratory for Geomechanics and Deep Underground Engineering, China University of Mining and Technology, Xuzhou, \\ Jiangsu 221116, China \\ ${ }^{2}$ School of Mechanics and Civil Engineering, China University of Mining and Technology, Xuzhou, Jiangsu 221116, China \\ ${ }^{3}$ School of Civil Engineering, Xuzhou Institute of Technology, Xuzhou, Jiangsu 221008, China \\ Correspondence should be addressed to Aihong Lu; xzlah@126.com
}

Received 30 July 2017; Accepted 10 October 2017; Published 9 November 2017

Academic Editor: Xinglin Lei

Copyright (c) 2017 Yanlong Chen et al. This is an open access article distributed under the Creative Commons Attribution License, which permits unrestricted use, distribution, and reproduction in any medium, provided the original work is properly cited.

\begin{abstract}
The instability of layer-crack plate structure in coal wall is one of the causes of rock burst. In the present paper, we investigate the formation and instability processes of layer-crack plate structure in coal wall by experiments and theoretical analysis. The results reveal that layer-crack plate structure formed near the free surface of the coal wall during the loading. During the formation of the layer-crack plate structure, the lateral displacement curve of the coal wall experiences a jagged variation, which suggests the nonlinear instability failure of the coal wall with a sudden release of the elastic energy. Then, a dynamic model for the stability analysis of the layer-crack plate structure was proposed, which takes consideration of the dynamic disturbance factor. Based on the dynamic model, the criterion for dynamic instability of the layer-crack plate structure was determined and demonstrated by an example. According to the analytical results, some control methods of dynamic stability of the layer-crack plate structure was put forward.
\end{abstract}

\section{Introduction}

Rock burst is a typical dynamic disaster for deep coal mining. During the rock burst, there is a huge release of elastic strain energy which can result in serious threats to the safety of coal mine production [1-3]. With the increase of the coal mining depth, the occurrence frequency of rock burst also increases in China [4-10]. Among the different kinds of rock burst, sloughing rock burst is the most common one, which usually results from the local instability of a mine roadway [11-13]. The sloughing rock burst not only brings harms to the support systems and human lives but also can cause other mine disasters, such as gas explosion [14-16]. The sloughing rock burst often occurs in areas with high stress and is caused by the formation and instability of layer-crack plate structure in coal wall near a roadway $[17,18]$, as demonstrated in Figure 1.
Roadway excavation always leads to the redistribution and concentration of the surrounding rock stress. Figure 1(a) shows the stress condition of the coal rib of the roadway, and Figure 1(b) displays the stress state of a microunit near the coal wall. When the depth of the roadway is high, the preexisting cracks in the surrounding rock expand and form a set of vertically extending wing cracks under high vertical stress, as displayed in Figure 1(c). These vertical cracks continually expand and combine, resulting in singlelayer or multilayer plate structures which are parallel to the rib of the road way (Figure 1(d)) and called layer-crack plate structure. Figure 2 shows some layer-crack plate structures in the field, which form around the surface of the rib of the roadway after the roadway excavation.

Based on engineering practices, many scholars have studied the coal wall instability in deep coal mining by simulation method and the elastic plate theory [19-26]. The internal 


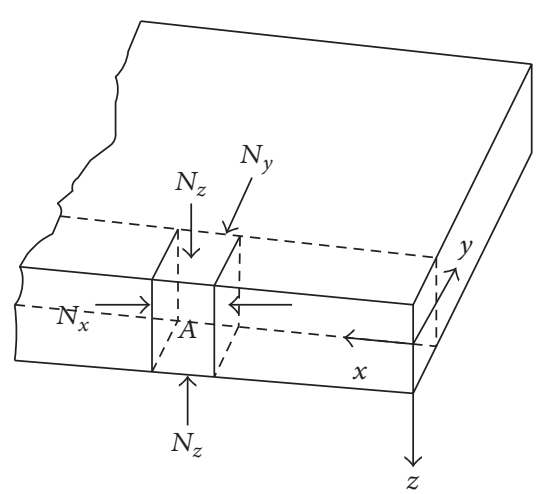

(a)

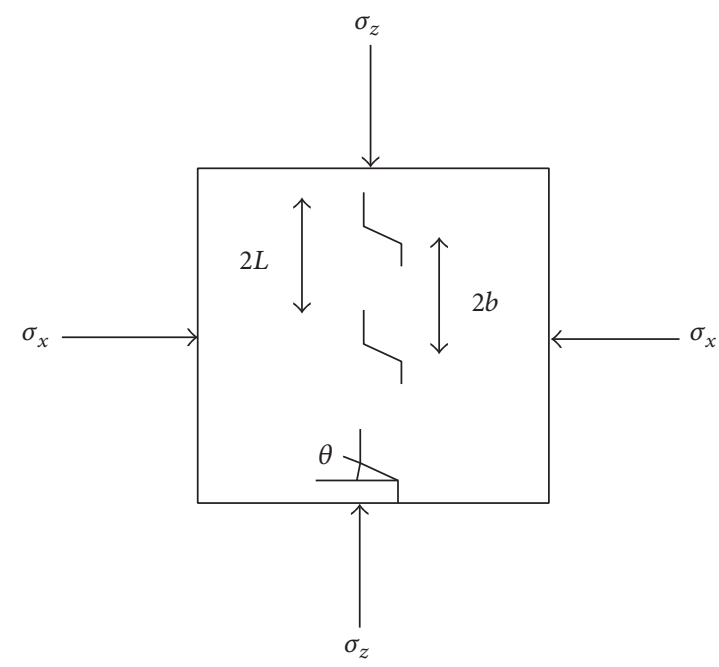

(c)

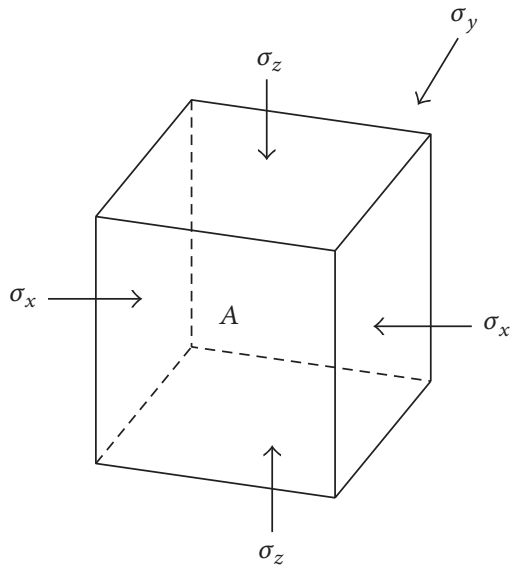

(b)

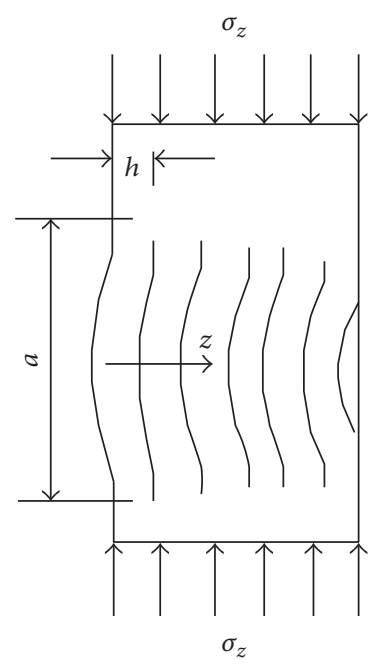

(d)

FIGURE 1: The formation process of the layer-crack plate structure in coal wall near a roadway.
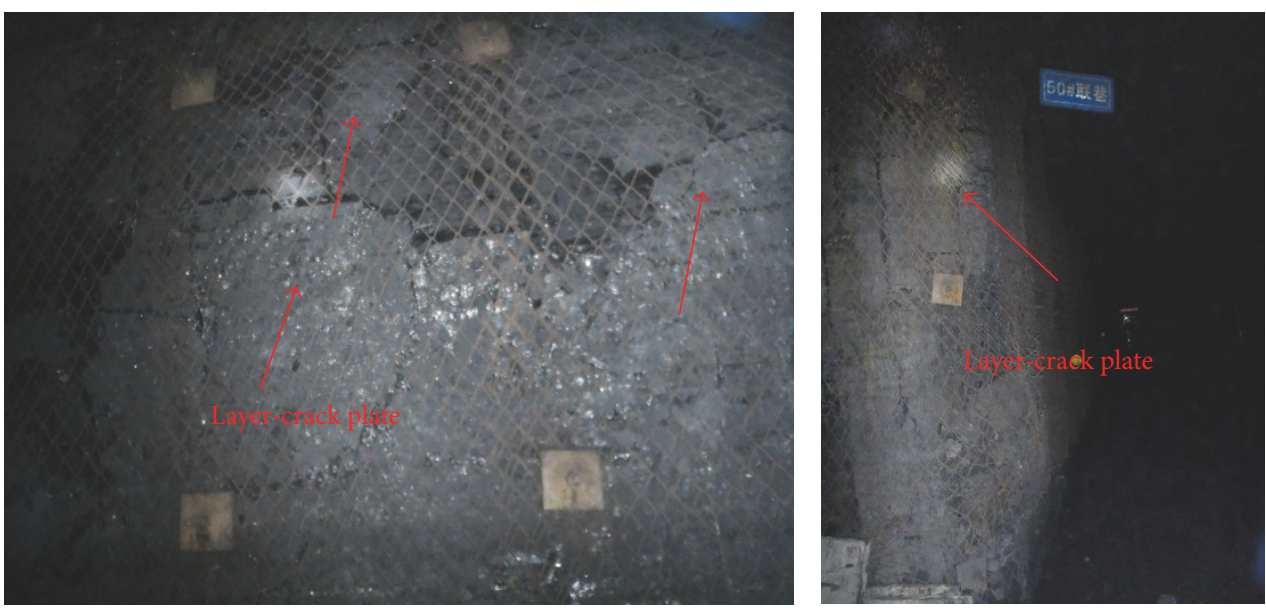

FIGURE 2: Layer-crack plate structure of the roadway coal wall. 


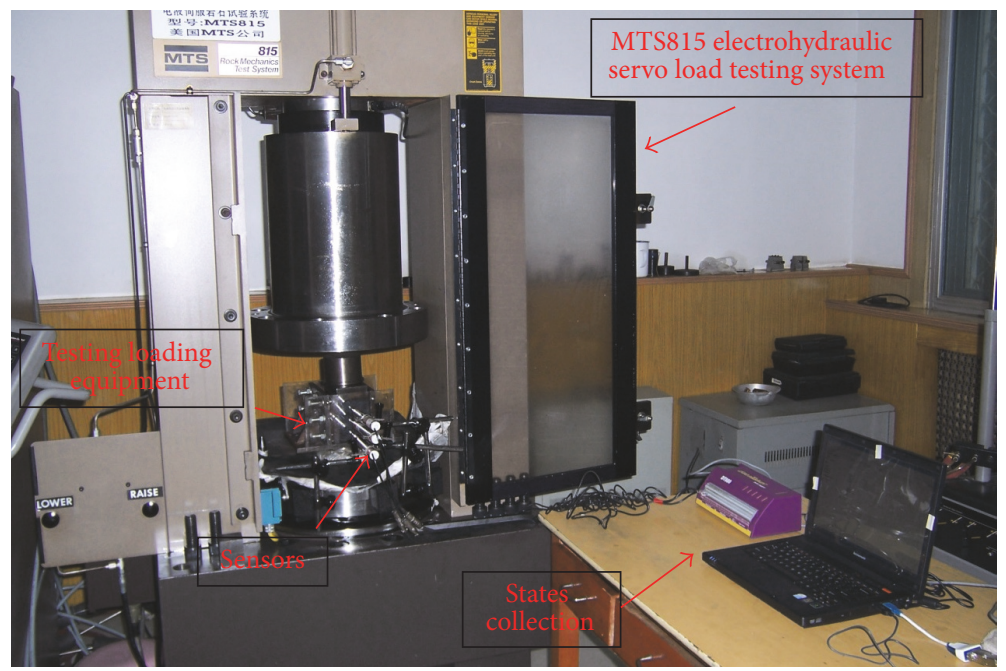

FIgURE 3: The overall test system of the experiment study.
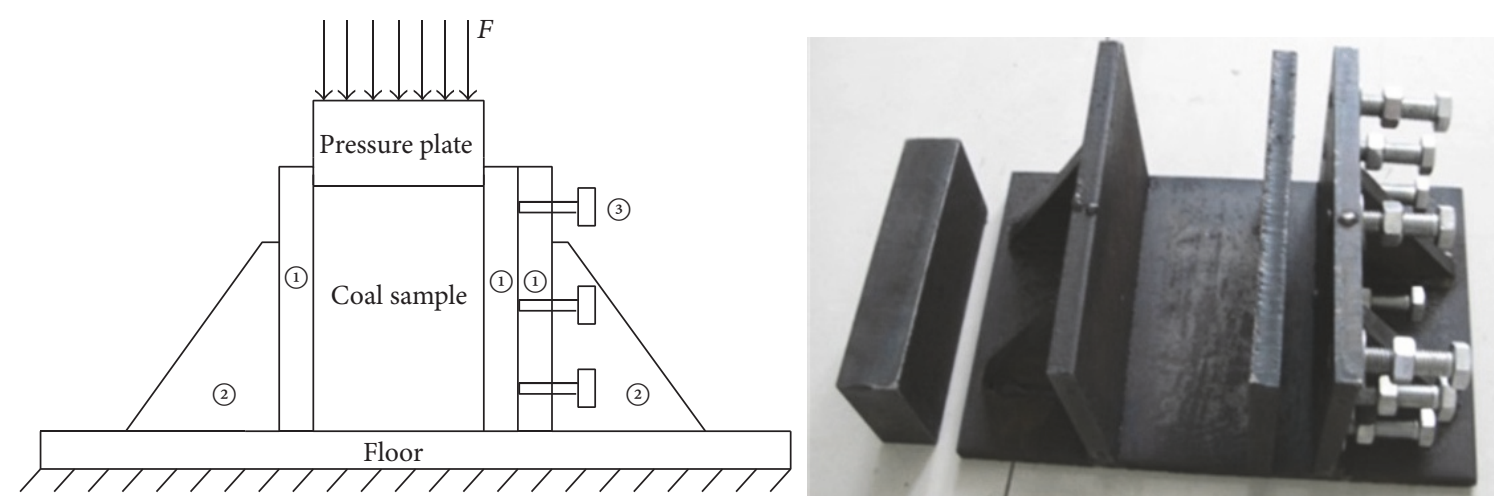

\footnotetext{
(1) lateral pressure plate

(2) Lateral reinforcement plate

(3) Adjusting nut
}

Figure 4: The loading device.

crack expansion and nonlinear instability features of the coal wall layer-crack structure were focused [27-32]. However, the formation mechanism of the layer-crack plate structure has not been validated by the laboratory test. In addition, the instability mechanism of the layer-crack plate structure is not cleared yet. Moreover, in the previous literatures, the dynamic disturbing load was not considered to analyze the stability of the layer-crack plate structure, which may result in an unsafe conclusion.

In the present paper, we discussed the forming process and stability of the layer-crack plate structure by experiments and theoretical analysis. First, some experiments were carried out in the laboratory to investigate the response of coal specimen during the formation of the layer-crack plate structure. Then, a dynamic model for the stability analysis of the layer-crack plate structure was proposed, which takes consideration of the dynamic disturbance. Based on the experimental and theoretical results, some measurements were put forward to control the instability of the coal wall.

\section{Experiment Study}

2.1. Test System. The test system (in Figure 3) consists of a MTS815 electrohydraulic servo loading system, a selfdesigned loading device, a displacement sensor, a data collection system, and other auxiliary devices. As displayed in Figure 4, a loading and restraint device is designed to provide specific stress conditions for the specimen. The device consists of a floor plate, lateral pressure plates, lateral reinforcement plates, adjusting nuts, and an upper (loading) pressure plate. These components are joined via highstrength welding.

During the testing, the loading device was placed on the loading platform of the MTS815 Testing System. The baseboard of the loading device was placed in horizontal contact with the loading platform. The MTS815 loading system applied vertical pressure to the coal specimen. To ensure that the pressure was uniformly distributed on the specimen, the upper pressure plate was placed on the top 
TABLE 1: Basic physical and mechanical parameters of the coal specimen.

\begin{tabular}{lccccccc}
\hline$\rho\left(\mathrm{g} / \mathrm{cm}^{3}\right)$ & $v(\mathrm{~km} / \mathrm{s})$ & $E(\mathrm{GPa})$ & $\lambda(\mathrm{GPa})$ & $\mu$ & $\sigma_{c}(\mathrm{MPa})$ & $\sigma_{t}(\mathrm{MPa})$ & $k$ \\
\hline 1.21 & 1.12 & 8.70 & 47.06 & 0.32 & 19.47 & 0.96 & 0.18 \\
\hline
\end{tabular}

Note. $\rho$ is density; $v$ is P-wave velocity; $E$ is Young's modulus; $\lambda$ is softening modulus; $\mu$ is Poisson's ratio; $\sigma_{c}$ is compressive strength; $\sigma_{t}$ is tensile strength; $k$ is burst tendency parameter, $k=E / \lambda$.

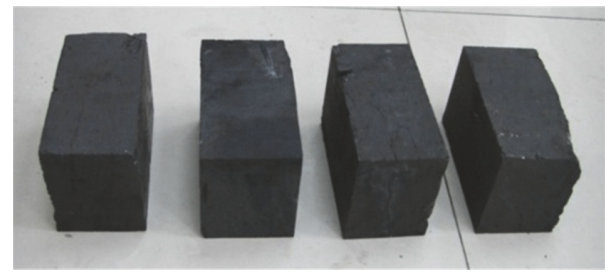

Figure 5: Coal specimens.

surface of the specimen. The lateral pressure plates provided lateral pressure for the specimen. The lateral resistance was in tight and uniform contact with the specimen. By adjusting the nuts on the fixed restraint plate, lateral displacement restraint on the specimen was applied. In order to ensure the stability of the lateral restraint plate, four lateral reinforcement plates were symmetrically welded to the two sides of the lateral restraint plate. To simulate the coal wall surface after roadway excavation, the front and back surfaces of the specimen were free. In addition, in order to minimize the friction between the steel plates and the sample, Vaseline was smeared on the contact surfaces to achieve the lubrication effect.

2.2. Specimens. Specimens were sampled from the working face of a coal mine. During the testing, when uniformly distributed pressure was applied on the top surface of the test system, the specimen deformation was symmetric to the middle section. To reduce the influence of free surface failure on the middle section during testing, the coal specimen were made into cuboids which are $150 \mathrm{~mm}$ in length, $100 \mathrm{~mm}$ in height, and $75 \mathrm{~mm}$ in width (Figure 5). The basic physical and mechanical parameters of the coal specimen are listed in Table 1.

It is necessary to test the rock burst tendency of coal samples before the instability test of coal wall layer-crack plate structure. The measurement method proposed by Zhang et al. [33] stated that the coal rock burst tendency can be characterized by the ratio of the elastic modulus $E$ to the softening modulus $\lambda$. Figure 6 shows the complete stressstrain curve of a standard coal specimen $(50 \mathrm{~mm}$ in diameter and $100 \mathrm{~mm}$ in height) under uniaxial compression. Here, a rock burst tendency factor $k$ is defined as $k=E / \lambda$, where $E$ and $\lambda$ are determined as described in the figure. Zhang et al. asserted that when $k \leq 0.5$ the coal rock burst tendency is very strong; $0.5 \leq k \leq 2$ implies that the rock burst tendency is relatively strong; $2 \leq k \leq 5$ indicates that the rock burst tendency is comparably weak; and when $k>5$, no rock burst tendency exists. The burst tendency factor of the specimen used in this study is 0.18 , which means that they have a very strong rock burst tendency.

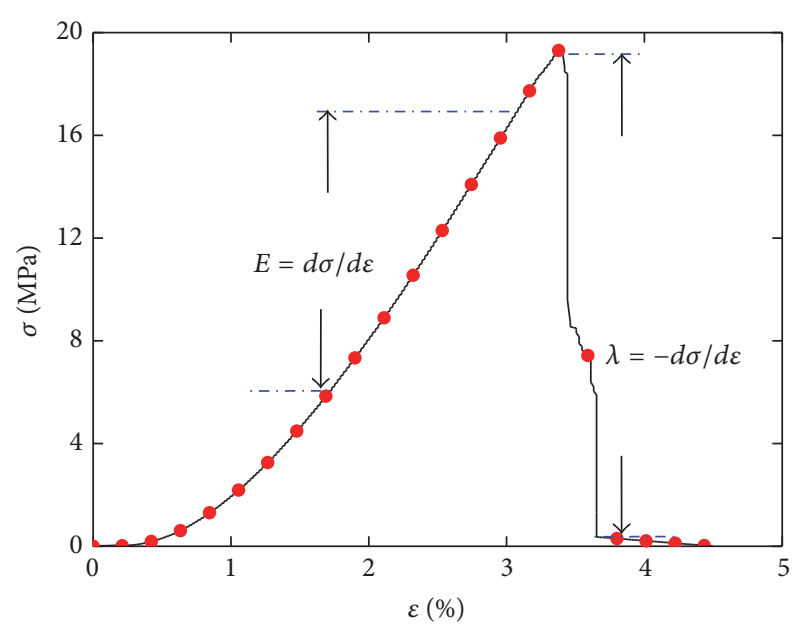

FIgURE 6: Complete stress-strain curve of a uniaxially compressed coal specimen.

\subsection{Test Scheme and Process}

2.3.1. Specimen Installation. Specimens were placed into the designed loading device, and the lateral displacement restraint was applied by adjusting the nuts.

2.3.2. Measuring Points. In order to obtain the deformation of the specimen, three measuring points (upper, middle, and lower) were uniformly arranged along the central line of the front free surface, as displayed in Figure 7. The displacement sensor was fixed on the loading baseboard by a magnetic stand.

2.3.3. The Loading Mode. In order to reduce the influence of the loading rate on the coal specimens, the displacement loading control mode was adopted, with a constant loading rate of $0.005 \mathrm{~mm} / \mathrm{s}$. The variables, such as axial displacement and force, were collected with a sampling interval of $0.25 \mathrm{~s}$.

2.4. Forming Process of the Layer-Crack Plate Structure. The experimental results show that the deformation characteristics of the four specimens are the same. Therefore, only the results of specimen $\# 1$ are used for demonstration. Figure 8 illustrates the curves of the lateral deformation at the three measuring points on the free surface of specimen \#1.

The formation and instability process of the layer-crack plate structures indicates the following.

(1) At the initial loading stage, the original defects inside the coal gradually close. The lateral deformation of the coal wall is relatively small, around $2 \mathrm{~mm}$. As the load increases, defects close and mutual compression takes place inside the 

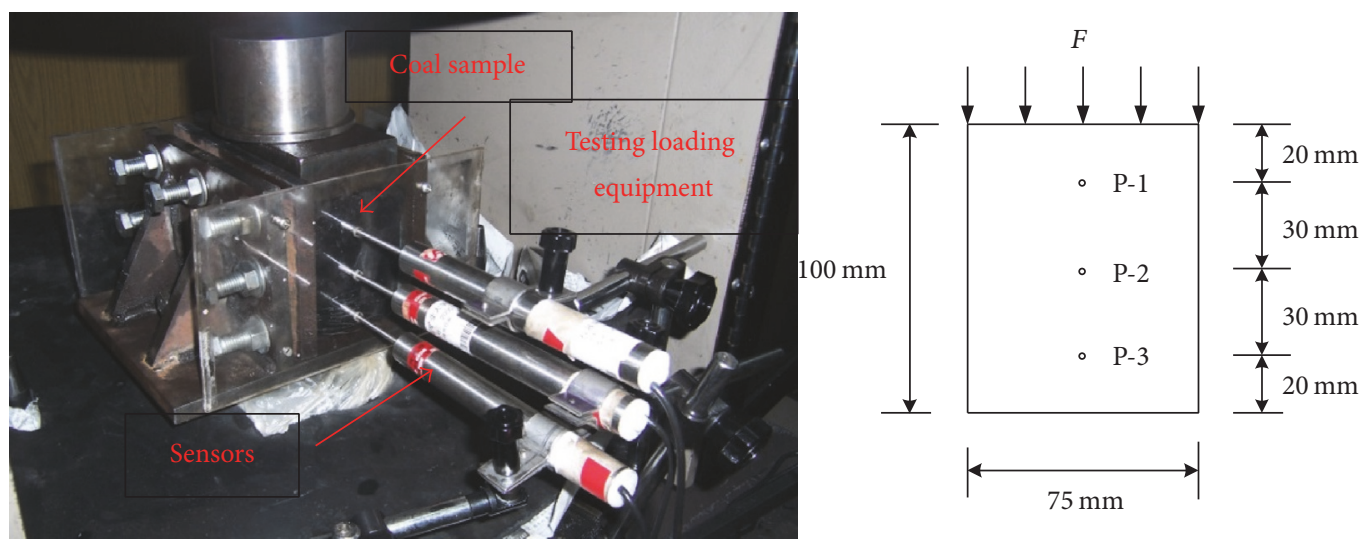

FIGURE 7: Arrangement of the measuring points.

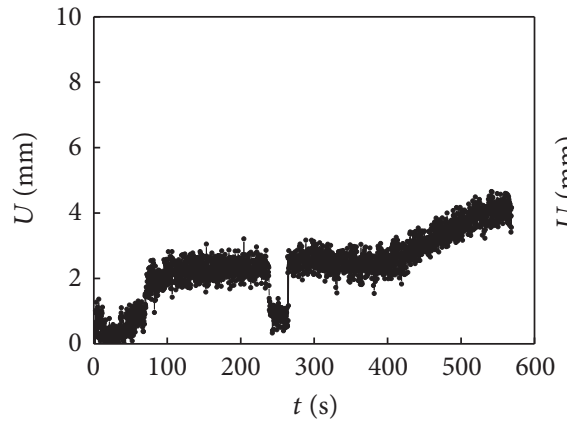

P-1

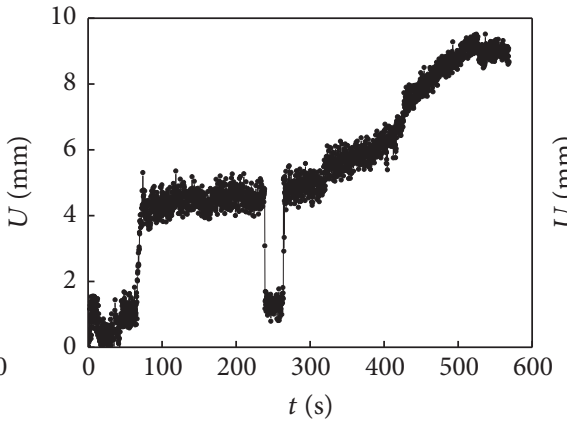

P-2

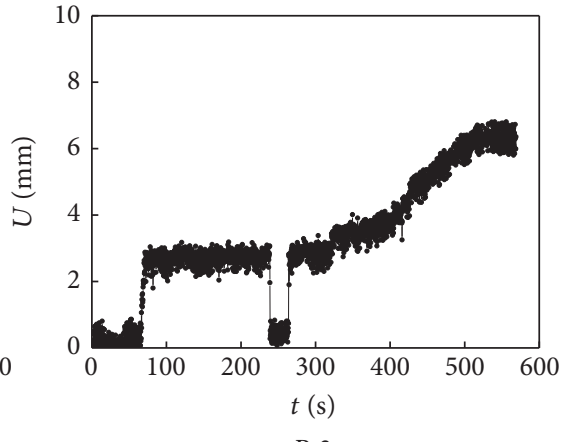

P-3

FIGURE 8: The deformation-time curves of the three measuring points.

coal, and the lateral deformation increases sharply when $t$ is about $75 \mathrm{~s}$. When $t$ is from 75 to $200 \mathrm{~s}$, the lateral deformation of coal wall continuously increases. At about $237.5 \mathrm{~s}$, the lateral deformation suddenly decreases and then returned to the original level after $30 \mathrm{~s}$. This is due to the peel-off of the free surface. With the increase of the load, the bearing capacity of the coal wall starts to reduce and the plate-like coal briquettes collapse one after another. Meanwhile, the lateral deformation quickly increases. After $526.5 \mathrm{~s}$, the coal specimen is broken into blocks.

(2) By comparing the deformation-time curves of the three measuring points, it is found that the middle measuring point (P-2) has the largest deformation, followed by the bottom measuring point (P-3), and the upper measuring point (P-1) has the smallest deformation. Because of the different boundary constraints, the three measuring points have the different deformation. As a result, the middle section of the coal wall fails first.

(3) From the experimental results, the lateral displacement curves of the coal wall present a jagged variation feature. When there are flake-like coal briquettes bulging in the coal wall, the displacement experiences a large and sudden jump. The jagged curve shape reflects the expansion and failure process of small defects inside the coal. Meanwhile, the large sudden jumps indicate the unstable failure feature of the coal wall with a sudden release of the elastic energy.

Figure 9 shows the specimen morphologies after failure. The figure indicates that, after failure, layer-crack plate structures form in all specimens with different layer width. The distribution features of the layer-crack plate structures present that splitting cracks near the free surface are relatively dense, while those far away from the coal wall surface are sparse. The distribution of the layer-crack plate structures in the in situ roadways displays the same character.

Observations on the failed coal walls show that there are vertically parallel cracks along the wall direction in the remaining intact block. There is also obviously a stripping layer gap between layer-crack plates. Some cracks have cut through the coal wall while some are still expanding. Several locally formed plate-crack rocks are peeling off. The platecrack rock, which has already peeled, appears to be plate-like and has lamellar morphologies. Meanwhile, observations on the peeled plate-like coal and coal wall show that the layercrack plate surface is rough and contains smooth surfaces along the coal wall direction. After the formation of layercrack plate structures, instability failure occurs under the continuous action of the load, such as the dynamic disturbance. 


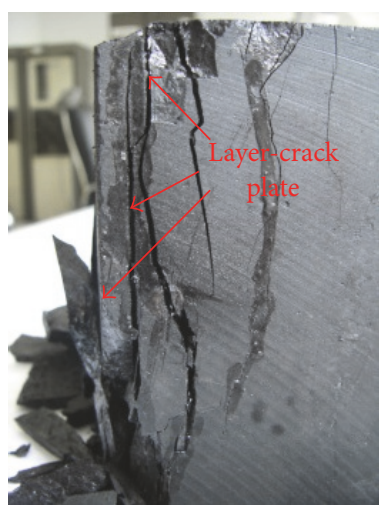

Sample 1

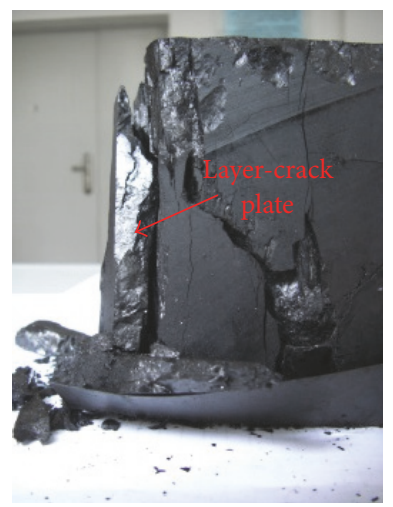

Sample 3

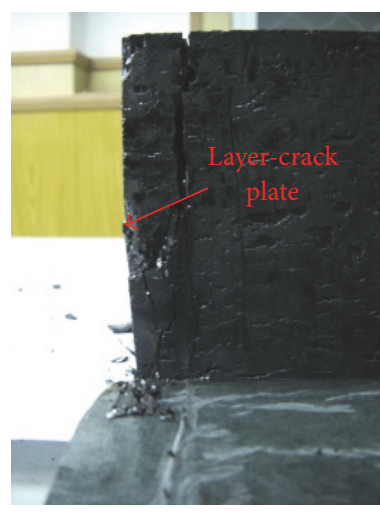

Sample 2

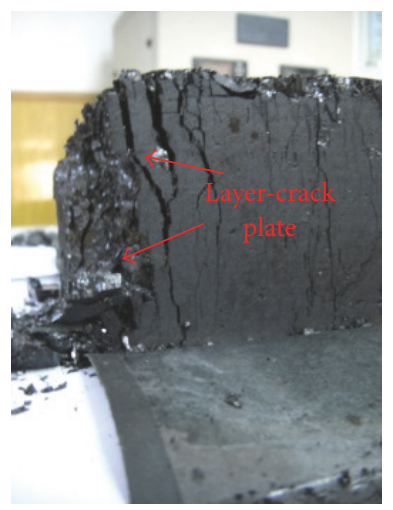

Sample 4
FIGURE 9: Characteristics of the layer-crack plate structures in the coal wall.

\section{Nonlinear Dynamic Mechanism of the Instability of the Layer-Crack Plate Structure}

After the formation of layer-crack plate structure in the coal wall, the internal storage energy of the structure continues to increase under the roof and floor clamping load. The energy will be released when small disturbance occurs, which will cause large area instability failure of the coal wall and induce the sloughing rock burst. During the mining process, various types of disturbing loads have significant impacts on the stability of coal walls, such as mine blasting, mechanical operation, and roof breakage. The disturbing load exerts a significant effect on the stability of the layer-crack plate structure. In this section, the dynamic stability analysis model of the layer-crack plate structure is established, and the nonlinear instability mechanism of the layer-crack plate structure of coal wall is revealed.

3.1. Establishment of the Mechanical Model. According to the mechanical characteristics of the layer-crack plate structure in coal wall, the proposed mechanical model is shown in Figures 10(a) and 10(b). For the model, $a$ is the height of the roadway; $b$ is the length along the roadway; and $h$ is the thickness of the layer-crack plate structure. The layer-crack plate structure of the surrounding rock is mainly subject to the pressure along the vertical direction of the plate $N_{x}$, the horizontal shear force $Q$, and the bending moment $M$. The layer-crack plate structure is subject to the inner rock mass and the disturbance effect load $q$. As is known, $q$ is the main inducing factor of instable failure. Because the cross length of the roadway is much smaller than its axial length and the force is approximately constant along the length direction of the roadway, the analysis can be regarded as a plane strain problem. It means that the layer-crack plate structure of the surrounding rock deforms uniformly along the horizontal direction. For the vertical direction, the layer-crack plate structure shows bending deformation under the pressure $N_{x}$ and the expansion effect of the coal wall.

According to the stability structure theory, the stability of the structure is mainly determined by the pressure $N_{x}$ along the vertical direction, the geometric size, and the constraint condition of the structure. When the integrity of coal near the upper and lower corners of the roadway is good and the corner of the layer-crack plate structure has a good constraint, the upper and lower ends of the layer-crack plate structure can be regarded as fixed constraints. The corresponding constraint model is shown in Figure 10(c). When the integrity of coal near the upper and lower corners of the roadway is bad, the upper and lower ends of the layer-crack plate structure can be regarded as simple supported constraints. The corresponding constraint model is shown in Figure 10(d).

The boundary conditions at both fixed and simply supported ends of the layer-crack plate structure are shown in

$$
\begin{aligned}
& \left.w(x, y, t)\right|_{\substack{x=0 \\
x=a}}=0, \\
& \left.\frac{\partial w(x, y, t)}{\partial x}\right|_{\substack{x=0 \\
x=a}}=0, \\
& \left.w(x, y, t)\right|_{\substack{x=0 \\
x=a}}=0, \\
& {\left.\left[\frac{\partial^{2} w(x, y, t)}{\partial y^{2}}+\mu \frac{\partial^{2} w(x, y, t)}{\partial x^{2}}\right]\right|_{\substack{x=0 \\
x=a}}=0,}
\end{aligned}
$$

where $w(x, y, t)$ is the deflection function of the layer-crack plate structure and $\mu$ is Poisson ratio of the material.

3.2. Dynamic Stability Control Equation. For the layer-crack plate structure of coal walls (Figure 10), the oscillation differential equation is

$$
\frac{\partial^{4} w}{\partial x^{4}}+2 \frac{\partial^{4} w}{\partial x^{2} \partial y^{2}}+\frac{\partial^{4} w}{\partial y^{4}}=\frac{1}{D}\left(N_{x} \frac{\partial^{2} w}{\partial x^{2}}-m \frac{\partial^{2} w}{\partial t^{2}}\right)
$$

where $m$ is the mass per unit volume of the layer-crack plate structure and $D=E h^{3} / 12\left(1-\mu^{2}\right)$ is the stiffness of the layercrack plate structure.

The deflection function is expressed in series form:

$$
w(x, y, t)=\sum_{k=1}^{\infty} f_{k}(t) \varphi_{k}(x, y),
$$

where $f_{k}(t)$ is the undetermined time function and $\varphi_{k}(x, y)$ is the natural vibration function. 


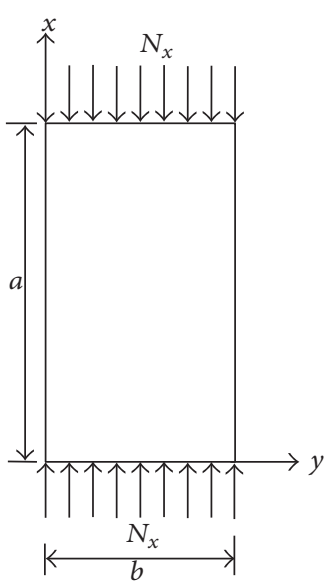

(a)

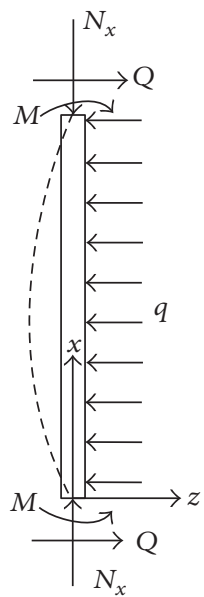

(b)

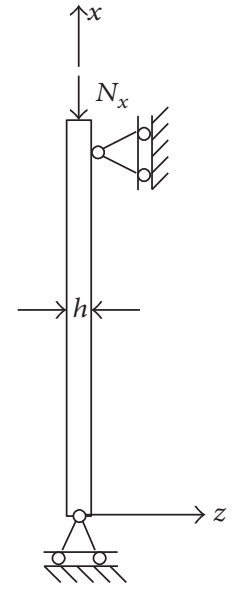

(c)

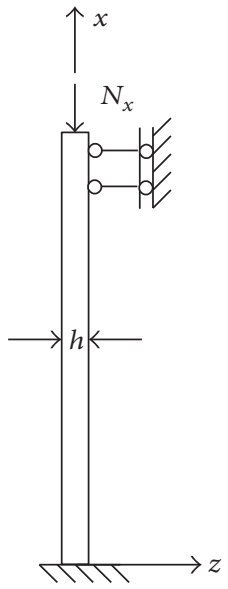

(d)

FIGURE 10: The mechanical model of the stability analysis of layer-crack plate structure: (a) the front view of the mechanics model; (b) the side view of the mechanics model; (c) two-end clamped; (d) two-end simply supported.

Equation (4) is obtained by substituting (3) into (2):

$$
f_{i}^{\prime \prime}+\omega_{i}^{2}\left[f_{i}-\sum_{k=1}^{\infty} F_{i k}(t) f_{k}\right]=0,
$$

where

$$
F_{i k}(t)=\frac{1}{m \omega_{i}^{2}} \int \varphi_{i}\left(N_{x} \frac{\partial^{2} \varphi_{k}}{\partial x^{2}}\right) d x .
$$

The disturbed effect of the dynamic load on the rectangular plate is analyzed. The internal force of the plate is expressed by the quasi-static stress in the plane problem, and the longitudinal inertia force is not considered. The expression is

$$
N_{x}(x, y, t)=\alpha N_{x}(x, y)+\beta \phi(t) N_{x t}(x, y),
$$

where $\alpha, \beta$ are the association coefficients. They can be determined by the invariant of the disturbance load and the periodic component.

Equation (7) is derived by substituting (6) into (4):

$$
\begin{aligned}
f_{i}^{\prime \prime}+c_{i k}\left[f_{i}-\alpha \sum_{k=1}^{\infty} a_{i k} f_{k}-\beta \phi(t) \sum_{k=1}^{\infty} b_{i k} f_{k}\right] & =0 \\
(i, k & =1,2,3, \ldots),
\end{aligned}
$$

where

$$
\begin{aligned}
& a_{i k}=\frac{1}{m \omega_{i}^{2}} \int \varphi_{i}\left(N_{x} \frac{\partial^{2} \varphi_{k}}{\partial x^{2}}\right) d x, \\
& b_{i k}=\frac{1}{m \omega_{i}^{2}} \int \varphi_{i}\left(N_{x t} \frac{\partial^{2} \varphi_{k}}{\partial x^{2}}\right) d x, \\
& c_{i k}=\frac{\delta_{i k}}{\omega_{i}^{2}} .
\end{aligned}
$$

The matrix form of (7) can be represented as

$$
f^{\prime \prime}+C^{-1}[I-\alpha A-\beta \phi(t) B] f=0,
$$

where elements in $A$ correspond with $a_{i k}$, elements in $B$ correspond with $b_{i k}$, elements in $C$ correspond with $c_{i k}$, and $I$ is the unit matrix. The characteristic equation of (9) is

$$
\begin{aligned}
& |I-\alpha A|=0 \\
& |I-\beta B|=0
\end{aligned}
$$

where $\alpha, \beta$ correspond with the solution of the static equation under external loads.

The natural vibration frequency of the layer-crack plate structure satisfies the following equation:

$$
\left|I-\omega^{2} C\right|=0 \text {. }
$$

And the stability equation of the layer-crack plate structure can be expressed by

$$
f_{k}^{\prime \prime}+\omega_{k}^{2}\left[1-\frac{\alpha}{\alpha_{k}}-\frac{\beta}{\beta_{k}} \phi(t)\right] f_{k}=0
$$

$$
(k=1,2,3, \ldots) \text {. }
$$

Equation (12) is a differential-integral Mathieu equation. $\alpha_{k}$ and $\beta_{k}$ are the load critical parameter values. They correspond to the dead load critical load values. $\omega_{k}$ is the natural vibration frequency value.

3.2.1. Two-End Clamped. The longitudinal load $N_{x}$ is reduced to the sum of the static pressure $N_{0}$ and the periodic load $N_{t} \cos \theta t$.

$$
N_{x}(t)=N_{0}+N_{t} \cos \theta t .
$$


The dynamic equation of the layer-crack plate structure under this condition is

$$
\begin{aligned}
\frac{\partial^{4} w}{\partial x^{4}} & +2 \frac{\partial^{4} w}{\partial x^{2} \partial y^{2}}+\frac{\partial^{4} w}{\partial y^{4}}-\frac{N_{0}+N_{t} \cos \theta t}{D} \frac{\partial^{2} w}{\partial x^{2}} \\
& +\frac{m}{D} \frac{\partial^{2} w}{\partial t^{2}}=0 .
\end{aligned}
$$

The vibration equation is

$$
\frac{\partial^{4} w}{\partial x^{4}}+2 \frac{\partial^{4} w}{\partial x^{2} \partial y^{2}}+\frac{\partial^{4} w}{\partial y^{4}}+\frac{m}{D} \frac{\partial^{2} w}{\partial t^{2}}=0
$$

According to the static boundary condition and the vibration boundary displacement condition of the layer-crack plate structure, the deflection function of the layer-crack plate structure in the case of simply supported ends is given as follows:

$$
\begin{aligned}
w(x, y, t)=A \sin \frac{n \pi x}{a} \sin (\omega t+\delta) & \\
& (n=1,2,3, \ldots) .
\end{aligned}
$$

The shape function can be expressed as

$$
\varphi_{n}(x, y)=A \sin \frac{\alpha \pi x}{a} .
$$

Natural vibrational differential equation can be achieved by substituting (17) into (15):

$$
\frac{\partial^{4} \varphi}{\partial x^{4}}+2 \frac{\partial^{4} \varphi}{\partial x^{2} \partial y^{2}}+\frac{\partial^{4} \varphi}{\partial y^{4}}-\frac{\omega^{2} m}{D} \varphi=0 .
$$

Natural vibration frequency can be obtained in the case of simply supported ends according to the energy method:

$$
\omega_{m}=\left(\frac{n \pi}{a}\right)^{2} \sqrt{\frac{D}{m}} .
$$

The dynamic stability equation can be achieved by substituting (19) into (12):

$$
\begin{aligned}
f_{n}^{\prime \prime}+\omega_{n}^{2}\left[1-\frac{N_{0}+N_{t} \cos \theta t}{\left(N_{n}\right)_{s}}\right] f_{m}= & \\
& (n=1,2,3, \ldots),
\end{aligned}
$$

where $\left(N_{n}\right)_{s}=\left(n^{2} \pi^{2} / a^{2}\right) D$ is the static and unstable critical load value of the layer-crack plate structure in the case of the simple support [32]. $n=1$ is used in the actual calculation.

3.2.2. Two-End Simply Supported. The kinetic equation and oscillation equation in the case of the fixed ends are the same as the case of simply supported ends, just like (14) and (15).

The expression of the deflection function in this condition can be expressed by

$$
w(x, y, t)=A \sin ^{2} \frac{n \pi x}{a} \sin (\omega t+\delta)
$$

Then the vibration-shape function is

$$
\varphi_{n}(x, y)=A \sin ^{2} \frac{\alpha \pi x}{a} .
$$

Take $n=1$, and then get the minimum natural frequency of the layer-crack plate structure:

$$
\omega=\left(\frac{\pi}{a}\right)^{2} \sqrt{\frac{16 D}{3 m}} .
$$

At this time, the dynamic stability equation of the layercrack plate structure is considered as follows:

$$
f^{\prime \prime}+\omega^{2}\left[1-\frac{N_{0}+N_{t} \cos \theta t}{(N)_{s}}\right] f=0,
$$

where $(N)_{s}=\left(4 \pi^{2} / a^{2}\right) D$ is the static and unstable critical load value of the layer-crack plate structure in the case of the fixed support [32].

3.3. Characteristics of the Dynamic Instability Zone. In the process of longitudinal load disturbance, the longitudinal dynamic disturbances are taken as the parameters of the loading system. When the disturbance frequency is located in the dynamic instability zone, the parameters of the layercrack plate structure are resonated and the structure will be unstable. In the process of calculation, the dynamic instability region is the infinite growth solution of the differentialintegral Mathieu equation.

Considering the correspondence with the longitudinal dynamic form of the boundary of the coal and rock mass, (9) can be expressed as

$$
f^{\prime \prime}+C^{-1}[I-\alpha A-\beta B \cos \theta t] f=0
$$

In this formula, $\alpha$ is the constant load component in the disturbance load and $\beta$ is the periodic load amplitude component in disturbance load. And $f(t)$ is

$$
f(t)=\sum_{k=1,3,5}^{\infty}\left(a_{k} \sin \frac{k \theta t}{2}+b_{k} \cos \frac{k \theta t}{2}\right),
$$

where $a_{k}$ and $b_{k}$ is time-independent vectors.

Apply (11) into (10), and consider that when the periodic component of the load is very small $(\beta \rightarrow 0)$, assuming that the load invariant component does not exist $(\alpha=0)$, then the first three representations of the critical frequency equation are

$$
\left|\begin{array}{ccc}
I-\frac{1}{4} \theta^{2} C & 0 & 0 \\
0 & I-\theta^{2} C & 0 \\
0 & 0 & I-\frac{9}{4} \theta^{2} C
\end{array}\right|=0 .
$$

The existence of the periodic solution is consistent with the equation and is determined by the following conditions:

$$
\left|I-\frac{k^{2} \theta^{2}}{4} C\right|=0 \quad(k=1,2,3, \ldots) .
$$

$$
(n=1,2,3, \ldots) \text {. }
$$


The characteristic quantity $1 / \omega_{k}^{2}$ of the matrix can be obtained from formula (11), and then the dynamic instability of the corresponding area can be found as

$$
\theta=\frac{2 \omega}{k} \quad(k=1,2,3, \ldots) .
$$

In (29), different $k$ values can be used to define different dynamic instability zones. When $k=1$, the first dynamic instability zone in the vicinity of $2 \omega$ is the most dangerous in practice, and its practical application is also the largest. This area is called the main dynamic instability zone.

For solving a specific problem, it can be assumed that the periodic solution on the boundary of the main dynamic instability zone has a harmonic property and satisfies the following form:

$$
f(t)=a \sin \frac{\theta t}{2}+b \cos \frac{\theta t}{2} .
$$

The approximation equation of the boundary of dynamic instability zone is

$$
\left|I-\alpha A \pm \frac{1}{2} \beta B-\frac{1}{4} \theta^{2} C\right|=0 .
$$

Let the diagonal elements in (31) be zero, and then the approximate expression of the boundary of the dynamic instability zone can be obtained.

3.3.1. Two-End Clamped. Equation (31) corresponds to the assumption of (30):

$$
\left|I-\left(N_{0} \pm \frac{1}{2} N_{t}\right) A-\frac{1}{4} \theta^{2} C\right|=0 .
$$

Let the diagonal elements of (32) be zero, and the approximate dynamic instability zone boundary can be obtained:

$$
\theta \approx 2 \omega_{m} \sqrt{1-\frac{\left(N_{0} \pm N_{t}\right)}{\left(m^{2} / a^{2}\right) D} \times \frac{m^{2}}{\pi a^{2}}} .
$$

When $m=1$, we can obtain the boundary of the main dynamic unstable area in simple constraint model:

$$
\theta=2 \omega \sqrt{1-\frac{\left(N_{0} \pm N_{t}\right)}{N_{c}}},
$$

where $\omega$ is the minimum natural frequency of this model and $N_{c}$ is the static minimum critical buckling load of the corresponding constraint model.

3.3.2. Two-End Simply Supported. The main dynamic instability zone of the fixed constraint model is the same as that of (34).

For (34), the expression is

$$
\frac{\theta}{2 \omega}=\sqrt{1-\frac{\left(N_{0} \pm N_{t}\right)}{N_{s}}} .
$$

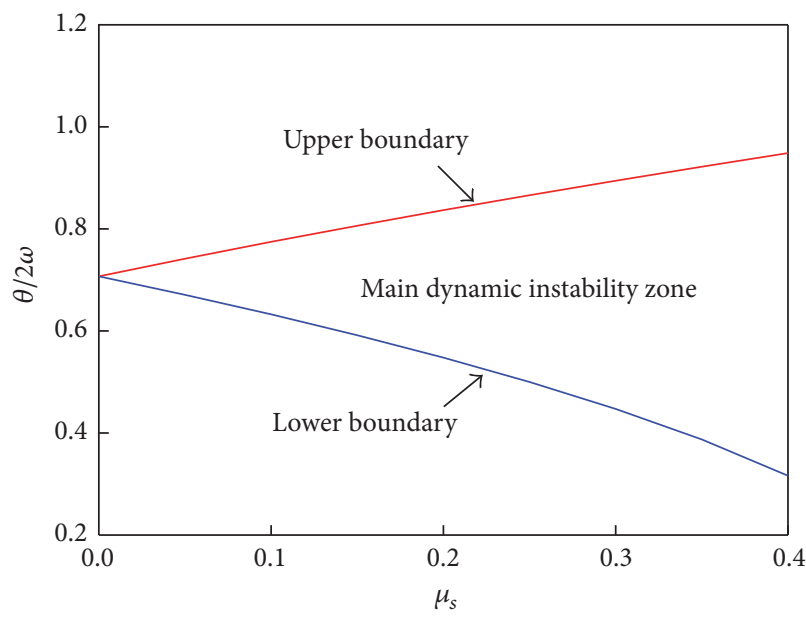

FIgURE 11: The main dynamic instability zone of layer-crack plate structure.

Suppose the longitudinal dynamic load of the layer-crack plate structure can be expressed by

$$
\begin{aligned}
& N_{0}=0.5 N_{s}, \\
& N_{t}=\mu_{s} N_{s} .
\end{aligned}
$$

In this formula, $0 \leq \mu_{s} \leq 0.4$, and it is called excitation rate.

According to (35), the boundary of the main dynamic instability zone of the layer-crack plate structure is obtained. As shown in Figure 11, the two boundary lines correspond to the main dynamic instability zone of the structure. When the longitudinal perturbation load frequency of the layer-crack plate structure is in the main dynamic instability zone, the plate will resonate and the structure will be unstable.

When the external disturbance load is constant, the elastic modulus of the layer-crack plate is small. The smaller the thickness is and the larger the height is, the smaller the natural frequency of the layer-crack plate structure. Then the possibility of external disturbance frequency in the dynamic instability zone is relatively decreased, and the resonance possibility of the layer-crack plate structure is reduced. Thus, the risk of dynamic instability is increased, and the risk of impact rock pressure is correspondingly reduced as well.

It is shown by (35) that the boundary of the dynamic instability zone of the layer-crack plate structure is closely related to the natural frequency of the layer-crack plate structure and the disturbance load. When the natural frequency of the layer-crack plate structure is constant, the boundary of the dynamic unstable zone depends on the size of the longitudinal disturbance load. When the static load amplitude of the vertical load is determined, the main dynamic instability zone expands as the amplitude of the periodic load increases. As shown in Figure 11, when $\mu$ is in the range of 0 to 0.4 , the main dynamic instability zone reaches the maximum value at $\mu=0.4$. At that time, the possibility that the external disturbance frequency is located in the dynamic unstable region and the possibility of 
structural parameter resonance become larger. Therefore, the risk of dynamic instability is increased.

3.4. Control of the Dynamic Stability of the Layer-Crack Plate Structure under Disturbance. The dynamic load pattern in a coal mine is complex and diverse. According to the operation in the coal mine, a simple example is given to illustrate the influence of drilling and blasting disturbance on the dynamic stability of coal walls.

According to literature [34] of blasting seismic wave propagation in rock mass recorded by field test, the dominant frequency range of blasting seismic wave which has the main influence on rock mass concentrated at $15 \sim 40 \mathrm{~Hz}$. The boundary of the coal wall of the roadway is considered as a simple constraint at both ends. The height and thickness of the layer-crack plate, rock mass medium elastic modulus, Poisson ratio, density, loading, and periodic load amplitude coefficient are as follows: $a=3 \mathrm{~m}, h=0.1 \mathrm{~m}, E=5 \mathrm{GPa}$, $\mu=0.3, \rho=1500 \mathrm{~kg} / \mathrm{m}^{3}, N_{0}=0.5 N_{c}, N_{t}=\mu_{s} N_{c}$, and $0 \leq \mu_{s} \leq 0.4$.

The main dynamic instability zone boundary of the layercrack plate structure can be expressed as

$$
\theta=2 \omega \sqrt{1-\frac{\left(N_{0} \pm N_{t}\right)}{N_{c}}} .
$$

Then we get the following formula:

$$
\omega=4\left(\frac{\pi}{a}\right)^{2} \sqrt{\frac{D}{3 m}} \approx 52.65 \mathrm{~Hz} .
$$

Considering the variation of the periodic load amplitude, we take $\mu$ in the range of 0 to 0.4 . When $\mu$ is 0.4 , the main dynamic instability zone reaches the maximum value. It can satisfy the following formula:

$$
0.31623 \leq \sqrt{1-\frac{\left(N_{0} \pm N_{t}\right)}{N_{c}}} \leq 0.94868 .
$$

The main dynamic instability zone of the coal wall is in the range of $33.3-100.13 \mathrm{~Hz}$. And the dominant frequency of blasting seismic wave is located in the main dynamic instability region. Under the influence of drilling and perturbation disturbance, the parameters will resonate and the cracked plate will be unstable, which may exert large-scale impact.

In order to maintain the stability of the structure, we should pay attention to the influence of the disturbance load on the stability. By controlling the range of the disturbance frequency of the dynamic load, the disturbance intensity is reduced to weaken the amplitude of the disturbance periodic load. This can avoid the main dynamic instability of the layercrack plate structure by preventing the occurrence of parameter resonance. Based on the above analysis and previous research $[35,36]$, the following measures are proposed.

3.4.1. Change the Natural Frequency of the Layer-Crack Plate Structure. Through grouting, strengthening support, and other measures, we can change the stiffness, control the damage degree and integrity, and change the longitudinal geometrical dimensions of the layer-crack plate structure.
3.4.2. Control the Dynamic Disturbance Frequency and Reduce the Disturbance Intensity. The main form of dynamic load in coal mine is drilling and blasting. Therefore, we can control the amount of explosives and change the location and depth of the hole. In the case of areas with high risk of instability, we can take short propulsion, less-dose smooth blasting. These practices can reduce the dynamic disturbance frequency, reduce the disturbance intensity, and reduce the amplitude of the periodic load to control the dynamic instability of the regional range.

\section{Conclusions}

This paper investigated the formation and instability processes of layer-crack plate structure in the coal wall based on experimental studies and theoretical analysis. The following conclusions can be drawn from our work.

(1) From the static loading test of strong rock burst tendency coal sample, the formation process of layer-crack plate structure in the coal wall is simulated. In loading process, the coal wall lateral displacement curves present a jagged variation tendency, which reflects the expansion of small defects in the coal wall. Meanwhile, sudden large jumps demonstrate the unstable failure features of the sudden release of elastic energy.

(2) After specimen failure, many layer-crack plate structures parallel with the free surface form. The splitting cracks near the free surface of the coal wall are relatively dense, while those inside the coal-body are comparably sparse.

(3) The nonlinear dynamic models of layer-crack plate structure under two conditions (two-end clamped, two-end simply supported) are established, and the dynamic stability control equation is proposed. By solving the equation, the main dynamic instability zone of layer-crack plate structure can be obtained. The effects of disturbance frequency, amplitude of disturbance load, and inherent characteristics of the cracked plate structure on the stability of the structure are investigated.

(4) When the amplitude of the disturbance load is the maximum, the boundary of the dynamic instability zone is the largest, and dynamic instability is mostly likely to happen in the layer-crack plate structure. By changing the natural frequency of the layer-crack plate structure controlling the dynamic disturbance frequency and reducing the disturbance intensity, the instability of the layer-crack plate can be prevented effectively.

\section{Conflicts of Interest}

The authors declare that there are no conflicts of interest regarding the publication of this paper.

\section{Acknowledgments}

The authors acknowledge financial support by the Fundamental Research Funds for the Central Universities (2015QNA60). 


\section{References}

[1] Q. M. Gong, L. J. Yin, S. Y. Wu, J. Zhao, and Y. Ting, "Rock burst and slabbing failure and its influence on TBM excavation at headrace tunnels in Jinping II hydropower station," Engineering Geology, vol. 124, no. 1, pp. 98-108, 2012.

[2] X. He and L. Song, "Status and future tasks of coal mining safety in China," Safety Science, vol. 50, no. 4, pp. 894-898, 2012.

[3] A. Mazaira and P. Konicek, "Intense rockburst impacts in deep underground construction and their prevention," Canadian Geotechnical Journal, vol. 52, no. 10, pp. 1426-1439, 2015.

[4] W. Cai, L. Dou, A. Cao, S. Gong, and Z. Li, "Application of seismic velocity tomography in underground coal mines: a case study of Yima mining area, Henan, China," Journal of Applied Geophysics, vol. 109, pp. 140-149, 2014.

[5] A. T. Iannacchione and S. C. Tadolini, "Occurrence, predication, and control of coal burst events in the U.S.," International Journal of Mining Science and Technology, vol. 26, no. 1, pp. 3946, 2016.

[6] C. A. Goode, A. Zona, and A. A. Campoli, "Controlling coal mine bumps," Coal Min (United States), vol. 21, no. 10, pp. 4853, 1984.

[7] W. Cai, L. Dou, S. Gong, Z. Li, and S. Yuan, "Quantitative analysis of seismic velocity tomography in rock burst hazard assessment," Natural Hazards, vol. 75, no. 3, pp. 2453-2465, 2014.

[8] A. Cao, L. Dou, W. Cai, S. Gong, S. Liu, and G. Jing, "Case study of seismic hazard assessment in underground coal mining using passive tomography," International Journal of Rock Mechanics and Mining Sciences, vol. 78, pp. 1-9, 2015.

[9] E.-Y. Wang and E.-L. Zhao, "Numerical simulation of electromagnetic radiation caused by coal/rock deformation and failure," International Journal of Rock Mechanics and Mining Sciences, vol. 57, pp. 57-63, 2013.

[10] G.-F. Liu, X.-T. Feng, G.-L. Feng, B.-R. Chen, D.-F. Chen, and S.-Q. Duan, "A Method for Dynamic Risk Assessment and Management of Rockbursts in Drill and Blast Tunnels," Rock Mechanics and Rock Engineering, vol. 49, no. 8, pp. 3257-3279, 2016.

[11] J. Wang, Y. Yubiao, J. Zhengjun, Q. Ping, and C. Chen, "Mechanism of energy limit equilibrium of rock burst in coal mine," Mining Science and Technology, vol. 21, no. 2, pp. 197-200, 2011.

[12] J.-A. Wang and H. D. Park, "Comprehensive prediction of rockburst based on analysis of strain energy in rocks," Tunnelling and Underground Space Technology, vol. 16, no. 1, pp. 49-57, 2001.

[13] S.-J. Miao, M.-F. Cai, Q.-F. Guo, and Z.-J. Huang, "Rock burst prediction based on in-situ stress and energy accumulation theory," International Journal of Rock Mechanics and Mining Sciences, vol. 83, pp. 86-94, 2016.

[14] Y. Yuan, S. Tu, Q. Wu, X. Ma, H. Tu, and L. Sun, "Mechanics of rib spalling of high coal walls under fully-mechanized mining," Mining Science and Technology, vol. 21, no. 1, pp. 129-133, 2011.

[15] H. Jin, Q. Hu, and Y. Liu, "Failure mechanism of coal and gas outburst initiation," in Proceedings of the 1st International Symposium on Mine Safety Science and Engineering, ISMSSE 2011, pp. 1352-1360, chn, October 2011.

[16] N. Aziz, D. Black, and T. Ren, "Mine gas drainage and outburst control in Australian underground coal mines," in Proceedings of the 1st International Symposium on Mine Safety Science and Engineering, ISMSSE 2011, pp. 84-92, chn, October 2011.
[17] J. M. Kemeny, "A model for non-linear rock deformation under compression due to sub-critical crack growth," International Journal of Rock Mechanics and Mining Sciences, vol. 28, no. 6, pp. 459-467, 1991.

[18] W. D. Ortlepp and T. R. Stacey, "Rockburst mechanisms in tunnels and shafts," Tunnelling and Underground Space Technology, vol. 9, no. 1, pp. 59-65, 1994.

[19] Q.-S. Bai, S.-H. Tu, X.-G. Zhang, C. Zhang, and Y. Yuan, "Numerical modeling on brittle failure of coal wall in longwall face-a case study," Arabian Journal of Geosciences, vol. 7, no. 12, pp. 5067-5080, 2014.

[20] D. Qian, N. Zhang, H. Shimada, C. Wang, T. Sasaoka, and N. Zhang, "Stability of goaf-side entry driving in 800-m-deep island longwall coal face in underground coal mine," Arabian Journal of Geosciences, vol. 9, no. 1, article no. 82, pp. 1-28, 2016.

[21] C. Liu, Z. Tan, K. Deng, and P. Li, "Synergistic instability of coal pillar and roof system and filling method based on plate model," International Journal of Mining Science and Technology, vol. 23, no. 1, pp. 145-149, 2013.

[22] J. X. Yang, C. Y. Liu, and B. Yu, "Mechanism of complex mine pressure manifestation on coal mining work faces and analysis on the instability condition of roof blocks," Acta Geodynamica et Geomaterialia, vol. 12, no. 1, pp. 101-108, 2015.

[23] M. Shabanimashcool and C. C. Li, "A numerical study of stress changes in barrier pillars and a border area in a longwall coal mine," International Journal of Coal Geology, vol. 106, pp. 39-47, 2013.

[24] L. Jiang, H. S. Mitri, N. Ma, and X. Zhao, "Effect of foundation rigidity on stratified roadway roof stability in underground coal mines," Arabian Journal of Geosciences, vol. 9, no. 1, pp. 1-12, 2016.

[25] C.-P. Lu, L.-M. Dou, B. Liu, Y.-S. Xie, and H.-S. Liu, "Microseismic low-frequency precursor effect of bursting failure of coal and rock," Journal of Applied Geophysics, vol. 79, pp. 55-63, 2012.

[26] M. He, L. R. e Sousa, T. Miranda, and G. Zhu, "Rockburst laboratory tests database - Application of data mining techniques," Engineering Geology, vol. 185, pp. 116-130, 2015.

[27] V. E. Panin, V. E. Egorushkin, L. S. Derevyagina, and E. E. Deryugin, "Nonlinear wave processes of crack propagation in brittle and brittle-ductile fracture," Physical Mesomechanics, vol. 16, no. 3, pp. 183-190, 2013.

[28] X. X. Miao, L. Q. An, and X. C. Zhang, "Model of rockburest for extension of slip fracture in palisades," Journal of China University of Mining and Technology, vol. 28, no. 2, pp. 113-117, 1999.

[29] X. C. Zhang, X. X. Miao, and T. Q. Yang, "The layer crack plate model and testing study of the rockburst in mines," Chinese Journal of Rock Mechanics and Engineering, vol. 18, no. 5, pp. 497-502, 1999.

[30] A. H. Lu, S. L. Yu, Q. Hao, and X. B. Mao, "Stability of layered crack structure in roadway surrounding rock under stress wave," Journal of China University of Mining and Technology, vol. 37, no. 6, pp. 769-774, 2008.

[31] W. H. Peng and A. H. Lu, "Numerical simulation of layered crack and failure of roadway surrounding rock under the action of stress wave," Journal of Mining and Safety Engineering, vol. 37, no. 6, pp. 213-216, 2008.

[32] M. Li, X. Mao, R. Mao, and J. Tao, "Study on buckling instability of surrounding rock based on cusp catastrophe model," Caikuang yu Anquan Gongcheng Xuebao/Journal of Mining and Safety Engineering, vol. 31, no. 3, pp. 379-384, 2014. 
[33] Z.-Z. Zhang, F. Gao, and X.-J. Shang, "Rock burst proneness prediction by acoustic emission test during rock deformation," Journal of Central South University, vol. 21, no. 1, pp. 373-380, 2014.

[34] J. C. Zhang and Q. F. Peng, "Field experiment and its analyses of attenuation law for seismic waves resulting from rock blasting," Liaoning Gongcheng Jishu Daxue Xuebao (Ziran Kexue Ban)/Journal of Liaoning Technical University (Natural Science Edition), vol. 20, no. 4, p. 399, 2001.

[35] J. He, L.-M. Dou, Z.-L. Mu, A.-Y. Cao, and S.-Y. Gong, "Numerical simulation study on hard-thick roof inducing rock burst in coal mine," Journal of Central South University, vol. 23, no. 9, pp. 2314-2320, 2016.

[36] Q. Yao, X. Li, F. Pan, T. Wang, and G. Wang, "Deformation and Failure Mechanism of Roadway Sensitive to Stress Disturbance and Its Zonal Support Technology," Shock and Vibration, vol. 2016, Article ID 1812768, 2016. 


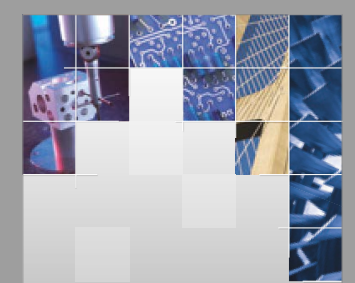

\section{Enfincering}
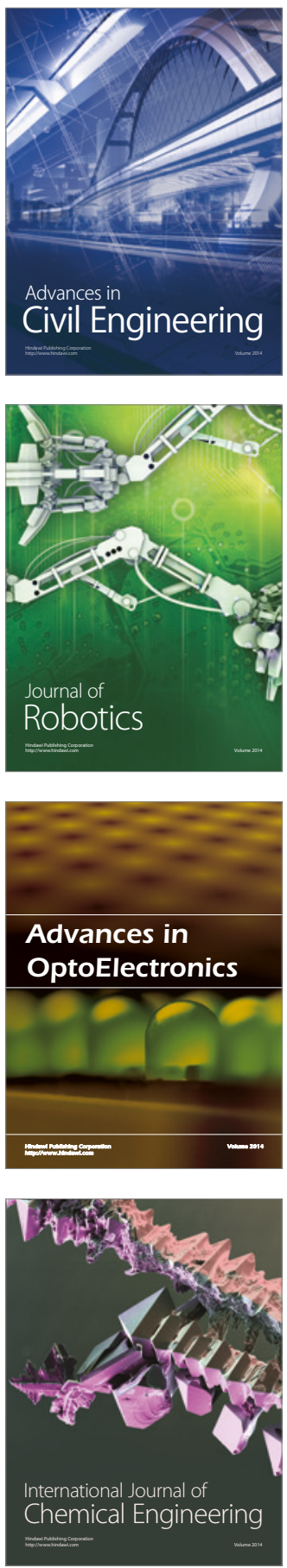

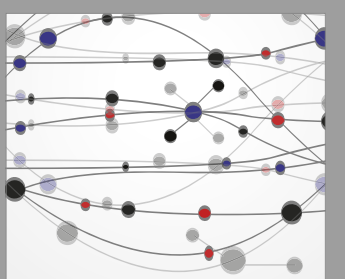

The Scientific World Journal

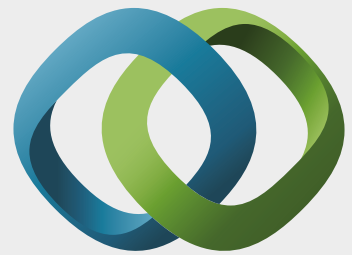

\section{Hindawi}

Submit your manuscripts at

https://www.hindawi.com
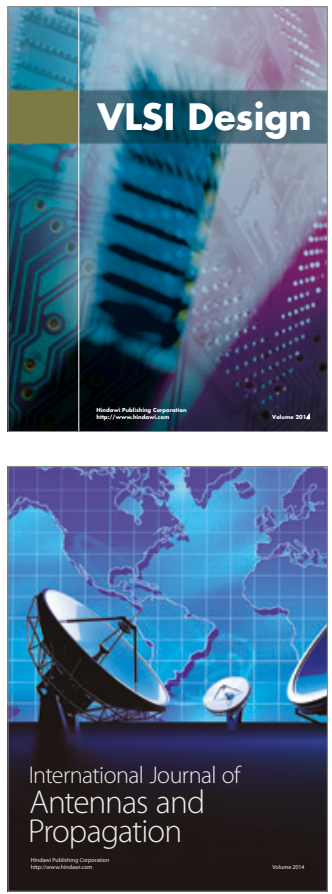

\section{Rotating}

Machinery
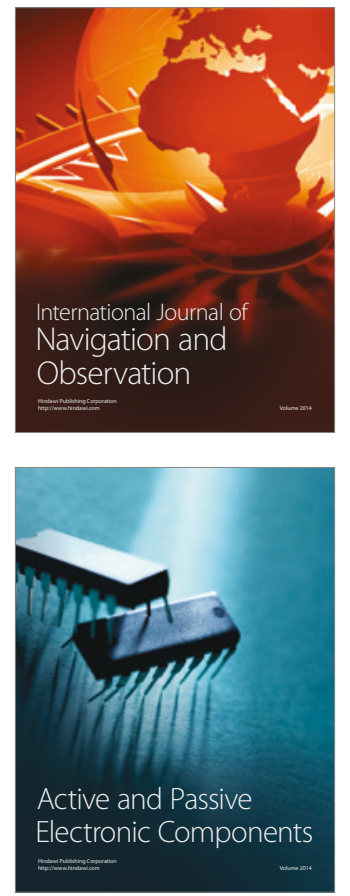
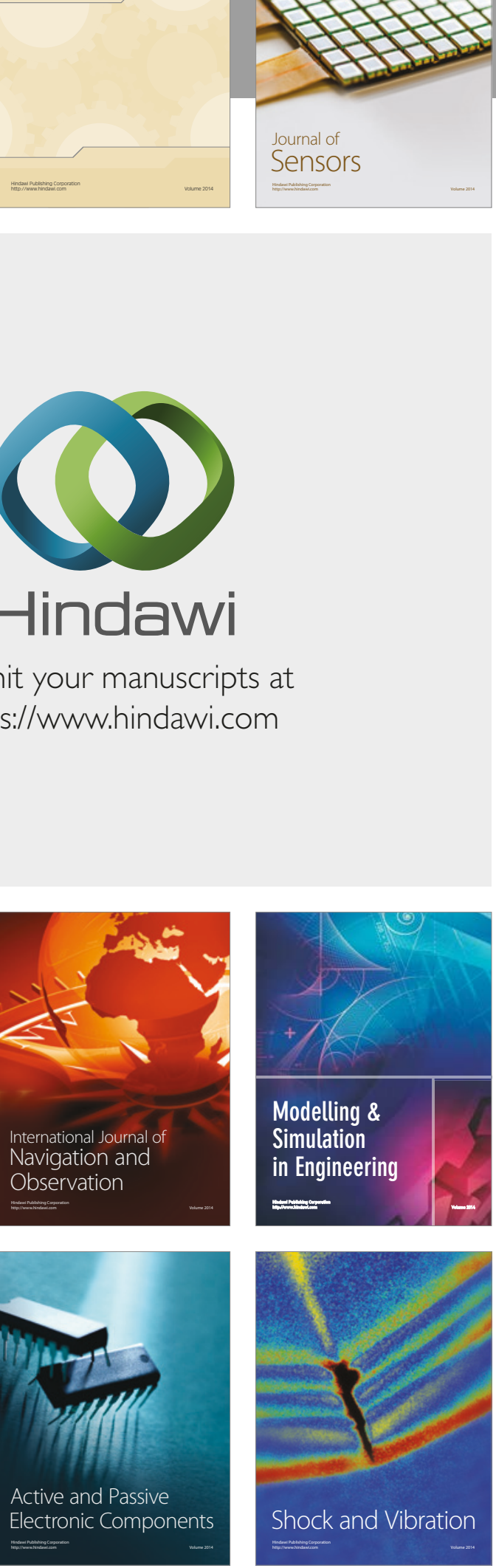
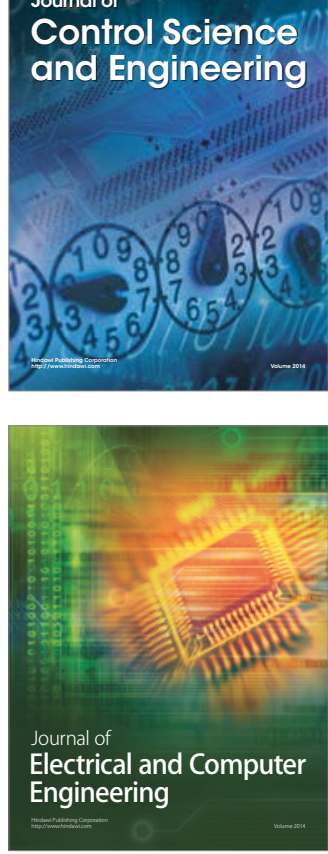

Distributed

Journal of

Control Science

and Engineering
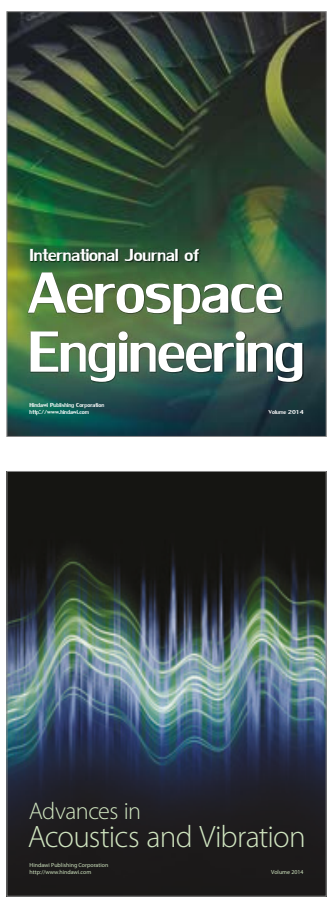

Sensor Networks 